\title{
Original Article (short paper) \\ Differences in game statistics between winning and losing for male wheelchair tennis players in Paralympics Games
}

\author{
Alejandro Sánchez-Pay \\ University of Murcia, Murcia, Spain \\ Gema Torres-Luque \\ University of Jaen, Jaen, Spain \\ Ángel Iván Fernandéz-Garcia \\ University of Granada, Granada, Spain \\ David Sanz-Rivas \\ Royal Spanish Tennis Federation, Madrid, Spain \\ José Manuel Palao Andrés \\ University of Wisconsin-Parkside, Wisconsin, United States
}

\begin{abstract}
Aims: The aim of the present study was to analyze the differences in wheelchair tennis game statistics between winning and losing sets. Methods: Data were collected from the 139 sets of 64 matches played by 64 males' players in the 2012 Paralympics Games. The variables studied were grouped in four groups: variables related to serve, to return, to winners and errors, and to net point. Data was collected from official website of the Paralympics Games. A univariate (Wilcoxon test) and multivariate (discriminant) analysis of data was done to the study the four groups of variable in relation to the result of the set (win or lose). Results: The result showed that winning players commit fewer errors and achieved more winning shots than losing players. Conclusion: The values presented could be used as a reference for practice and competition in wheelchair tennis players.
\end{abstract}

Keywords: notational analysis, match analysis, racket sports, performance indicators;

\section{Introduction}

Match analysis is an area of sports science that describes the analysis of sports competition. In conventional tennis, using match statistics data, it is possible to better define player's performance and individual characteristics (e.g. gender and age $)^{1}$, winning or losing of matches ${ }^{2}$, playing patterns on different surfaces ${ }^{3}$, or against different opponents (right and left handers $)^{4}$. A statistical analysis of match characteristics allows us to increase the knowledge about winning or losing a match ${ }^{5}$. There is not much information about the tactical wheelchair tennis competition, so the training system is based on information from conventional tennis.

The main difference compared to conventional tennis rules and wheelchair tennis is that the ball can bounce twice before being hit ${ }^{6}$. This rule allows players to hit balls far as its ability to displacement from conventional tennis is lower? ${ }^{7}$. The displacement capacity is determined largely by the type of injury the player, so players with less severe injury will be faster than players with a more severe injury ${ }^{8}$. The type of injury will allow the player to sit higher or lower in his chair, although the height of hit the ball will always be lower than a conventional tennis player ${ }^{7}$. This lower position the wheelchair tennis player, could affect the action mainly serve, performing as many double faults and fewer aces ${ }^{9}$. These differences with conventional tennis affect the dynamics of the game. Therefore, the aspects and the values that differentiate winning players from the losers in conventional tennis, such as numbers of aces, double faults, errors, point won on first and second serve, winner, break points won, etc. ${ }^{10}$, could not be applicable in wheelchair tennis. The aim of the present study was to analyze the differences in game statistics of wheelchair tennis between winning and losing sets.

\section{Methods}

\section{Samples}

Data from 139 sets of 64 single male matches played on the 2012 Paralympics Games were analyzed. All the matches were played on hard court. The sample represents $100 \%$ of all matches played by 64 male players. In this tournament played the best international ranking players with qualifying through competition system. Data for the study were gathered from the official website of the Paralympics Games (accessed 13th October 2012). All matches were played best of three set with tie break in all sets. The criteria for matches to be included in the study were that the match had to be a completed match. The studied 
variables were divided into four groups (Table 1). The study was undertaken according to the Helsinki declaration, and all procedures were approved by the Bioethics Commissions of the University of Murcia (1431/2017).

Table 1. Variables studied in the wheelchair tennis competition from the Paralympics Games London 2012.

Group of variables

Variables or game statistics or performance indicators
Variables related to points serve

Variables related to points return

Variables related to winners and errors

Variables related to net points
Total aces, double faults, points played on first serve, total points played on serve, percentage of first serves in, aces on first service, aces on second service, points won on first serve, percentage of points won on first serve, points played on second serve, points won on second serve and percentage of points won on second serve.

Receiving points won, receiving points played, percentage of receiving points won, break points won, break point opportunities, percentage of break points won, and returns of serve winners.

Total winners, forehand winners, backhand winners, forced errors, unforced errors, and total points won.

Net points won, net points played and percentage of net points won.

Note: Data was obtained from the official statistics of the Paralympics Games (http://www.london2012.com/paralympics).

\section{Procedure}

The data were obtained from the official statistics of the tournament. The data were recorded in a specific spreadsheet for processing. The unit of analysis was the set. From the spreadsheet, data was exported to SPSS 19.0 for its analysis.

\section{Statistical analysis}

Firstly, a descriptive analysis of the data was done (average values and standard deviations). Secondly, a Wilcoxon test (nonparametric) was carried out with the goal of analyzing the differences between winning and losing players. Finally, a discriminant analysis ${ }^{11}$ was done to find those statistical variables that best differentiate winning and losing players. Structural Coefficients (SC) greater than or equal to $|.30|^{12}$ were considered relevant for the interpretation of the linear vectors. All of the statistical analyses were done with a level of significance of $p \leq 0.05$.

\section{Results}

Regarding to point serve variables (Table 2), winning players had significantly higher values for the following variables: total aces, percentage of first serve, aces on first serve, points won on first serve, percentage of points won on first serve, points won on second serve, and percentage of points won on second serve. On the other hand, losing players had significantly higher values for the variables: double faults, and points played on second serve, and non-significantly for the points played on serve. For the rest of variables, no significant differences were found.

For the variables regarding the return points, winning players had significantly higher averages values in the following variables: receiving points won, percentage of receiving points won, break points won, break point opportunities, percentage of break points won, and returns on serve winners. No significance differences were found in the variable receiving points played.

For the variables regarding the winners and errors, significant differences were found in all variables. Winning players had significantly higher averages for the following variables: total winners, forehand winners, backhand winners, and total points won. Losing players had significantly higher averages for the variables forced errors, and unforced errors. For the net points variables, winning players had significantly higher averages values in all variables: net points won, net points played, percentage on net points won.

The multivariate analysis showed that the discriminant function obtained was significant $(\mathrm{p}<0.001)$, and it correctly classified $99.6 \%$ of winning and losing players (Table 3 ). The variables which allow us to better discriminate the category winners or losers were the break points won $(\mathrm{SC}=0.35)$, and percentage of points won on first serve $(\mathrm{SC}=0.35)$.

Table 2. Differences between winning and losing wheelchair tennis players in game statistics from the 2012 Paralympics Games. Media (M) and Standard Deviation (SD).

\begin{tabular}{lccccc}
\hline \multicolumn{1}{c}{ Variables } & \multicolumn{2}{c}{ Loser set } & \multicolumn{2}{c}{ Winner set } & $\mathbf{p}^{1}$ value \\
\cline { 2 - 5 } & $\mathbf{M}$ & SD & M & SD & \\
\hline Variables related to points serve & & & & & \\
Total aces & .54 & .92 & 1.18 & 1.23 & .000 \\
Double faults & 2.37 & 1.77 & 1.63 & 1.52 & .000 \\
\hline
\end{tabular}




\begin{tabular}{|c|c|c|c|c|c|}
\hline Points played on first serve & 17.12 & 7.12 & 17.32 & 6.71 & .743 \\
\hline Total points placed on serve & 27.48 & 9.06 & 26.12 & 8.86 & .198 \\
\hline First serve $(\%)$ & 61.72 & 12.62 & 66.20 & 12.11 & .005 \\
\hline Aces on first serve & .47 & .81 & 1.08 & 1.17 & .000 \\
\hline Aces on second serve & .06 & .27 & .10 & .33 & .261 \\
\hline Points won on first serve & 8.40 & 4.72 & 12.05 & 3.60 & .000 \\
\hline Points won on first serve (\%) & 47.17 & 14.22 & 72.50 & 12.94 & .000 \\
\hline Points won on second serve & 3.51 & 2.36 & 4.58 & 2.26 & .000 \\
\hline Points played on second serve & 10.40 & 4.49 & 8.82 & 4.17 & .003 \\
\hline Points won on second serve (\%) & 32.01 & 17.12 & 53.74 & 19.02 & .000 \\
\hline \multicolumn{6}{|l|}{ Variables related to points return } \\
\hline Receiving points won & 10.67 & 6.16 & 14.47 & 5.71 & .000 \\
\hline Receiving points played & 26.23 & 9.05 & 27.40 & 9.06 & .244 \\
\hline Receiving points won (\%) & 38.51 & 14.51 & 53.22 & 14.30 & .000 \\
\hline Break points won & .80 & .96 & 2.73 & .73 & .000 \\
\hline Break points opportunities & 2.35 & 2.41 & 5.06 & 2.27 & .000 \\
\hline Break points won $(\%)$ & 40.52 & 33.83 & 61.28 & 22.75 & .000 \\
\hline Return of serve winners & 1.53 & 1.73 & 3.05 & 2.30 & .000 \\
\hline \multicolumn{6}{|c|}{ Variables related to winners and errors } \\
\hline Total winners & 7.42 & 4.84 & 12.55 & 4.98 & .000 \\
\hline Forehand winners & 3.80 & 2.74 & 6.68 & 3.11 & .000 \\
\hline Backhand winners & 2.54 & 2.41 & 3.77 & 2.41 & .000 \\
\hline Forced errors & 12.85 & 4.41 & 8.72 & 5.04 & .000 \\
\hline Unforced errors & 6.47 & 3.65 & 5.12 & 3.91 & .000 \\
\hline Total points won & 21.51 & 9.99 & 32.19 & 6.09 & .000 \\
\hline \multicolumn{6}{|l|}{ Variables related to net points } \\
\hline Net points won & 1.58 & 1.82 & 2.46 & 2.16 & .000 \\
\hline Net points played & 3.07 & 2.90 & 3.82 & 3.04 & .014 \\
\hline Net points won (\%) & 51.44 & 37.35 & 63.96 & 32.01 & .010 \\
\hline
\end{tabular}

${ }^{1}$ Wilcoxon test.

Table 3. Standardized coefficients from the discriminant analysis of the game statistics between winning and losing wheelchair tennis players in the 2012 Paralympics Games.

\begin{tabular}{lc}
\hline \multicolumn{1}{c}{ Game statistics variable } & Winner-Loser \\
\hline Break points won & $-.35^{*}$ \\
Points won on first serve (\%) & $-.35^{*}$ \\
Break points won (\%) & -.22 \\
Receiving points won (\%) & -.22 \\
Points won on second serve (\%) & -.21 \\
Net points won & -.20 \\
\hline
\end{tabular}


Total points won

Total aces

Points won on first serve

Aces on first serve

Points played on second serve

Returns on serve winners

First serve (\%)

* SC discriminant value $\geq|.30|$

\section{Discussion}

The purpose of this study was to analyze the differences in wheelchair tennis game statistics between winning and losing sets. The winner of a set seems to be more offensive (winning shots) and make fewer errors. These findings provide new knowledge that may help to understand wheelchair tennis more comprehensively and could be used to design training drills. The results of this study show that winning players have better game statistics in a serve situation, both in the number of aces per set, and points won on first and second serve. The percentage of first serves for the winner is similar to previous studies 9 . These values are also similar to conventional tennis ${ }^{3,13}$. This could indicate that the winners of the set have a better control of the serve situation than losing players, with better control of effects, direction and hitting power in the serve, as happens in conventional tennis ${ }^{14}$.

Winning players have a significantly higher number of aces and lower number of double faults per set than losing players. These values are lower than those found in conventional tennis ${ }^{15,16}$. This shows the difficulty for the wheelchair player to win points with the serve. This is likely caused by the fact that wheelchair tennis players play in a lower position compared to conventional tennis players ${ }^{7}$. Winning players seem to have the ability to make fewer serve errors, decreasing the number of double faults, so by playing safely, the highest numbers of points are won. This information is useful to understand the game dynamic and can help to design specific training and goals for this sport (e.g. data allow us to know the serve ace-error ratio that can be used as a goal for this population). 
Regarding the return, winners had a significantly higher number of points than losers. These differences may be due to two aspects. Firstly, the loser does not dominate with his serve so does not gain winning points, and secondly, the winner makes more offensive returns with the intention to have the initiative. The values found in wheelchair tennis were higher than in conventional tennis ${ }^{10,16}$. The reason for the differences between wheelchair tennis players and conventional tennis players could be that the wheelchair or the player's injury does not allow the player to use the entire kinetic chain (lower body). Additionally, the contact height is lower, and the server, after serving, has to move quickly from a static to a dynamic situation ${ }^{7}$.

Winners convert more break points than the loser. The values found are higher than in conventional tennis ${ }^{10,16}$. These differences, close to $20 \%$, show that wheelchair tennis players are more likely to break serve than in conventional tennis. The cause, as mentioned previously, is properly related to the serve being less aggressive in wheelchair tennis than in conventional tennis.

Winning players presented almost twice as many winning returns and more winning shots than the loser. This could be because winning players have a better technical-tactical control in hitting (direction, distance, spin, and power), are more offensive/ aggressive, and/or competence with the wheelchair (recoveries, movement speed, and position). The ratio of winning shot per points is slightly better in wheelchair tennis than in conventional tennis ${ }^{16}, 1: 2.56$ and $1: 2.75$, respectively.

Winning players presented better outcomes than losing player in all variables. Losing players had a similar number of net points than winning players (about 3-3.8 times per set), but wining players had better effectiveness than losing players $(64 \%$ vs 51). These values are lower than in conventional tennis ${ }^{2,13}$, which seems to indicate than net points are less common in the wheelchair tennis game.

Considering together all the actions studied, two variables were found to best represent the difference between winning or losing, break points won and percentage of points won on first serve. Therefore, winning players have the capacity with their first serve to difficult returner's action and they are more aggressive or effective returning the serve, making lower number of errors during the match.

Future studies are need in wheelchair tennis to increase the knowledge about this sport. The kind of injury and physical capacities and skills may have an influence on the serve, concerning the impact point, the people with more stability could produce and hit the ball with a greater angle from the top ${ }^{7}$. Therefore, this relationship must be studied in order to know their relationship with technical-tactical actions and with the result of the set.

Wheelchair tennis is one of the adapted sports which has most grown competitively in the last decade. In search of professionalism, it is necessary to know what the differences are that determine the possibility to win or lose a match. Winner gets the greatest number of aces, percentage of points won on first and second serve, and return points and break points won. The winning wheelchair tennis player is a more offensive player (greater number of winning shots) and does fewer errors) than the loser. The differences in the role of the serve, the importance of the return actions, or the efficacy percentage must be considered when working with male WT players. With this study it has been advanced that match statistics may be used to distinguish players results. Wheelchair tennis coach's can used these values to establish goal setting in its exercises and to achieve high performance levels playing wheelchair tennis. Our data may contribute to a better understanding of wheelchair tennis and may help to design training drills according the real needs from the game situation.

\section{References}

1. Hizan H, Whipp P, Reid M. Gender differences in the spatial distributions of the tennis serve. Int J Sport Sci Coach. 2015; 10(1): 87-96.

2. O 'Donoghue P, Ingram B. A notational analysis of elite tennis strategy. J Sports Sci. 2001; 19(2): 107-115. doi:10.1080/026404101300036299.

3. Barnett T, Meyer D, Pollard G. Applying match statistics to increase serving performance. J Med Sci Tennis. 2008; 13(2): 24-27.

4. Loffing F, Hagemann N, Strauss B. Automated processes in tennis: do left-handed players benefit from the tactical preferences of their opponents? J Sports Sci. 2010; 28(4): 435-443. doi: $10.1080 / 02640410903536459$.

5. Filipčič A, Caks K, Filipčič T. A comparison of selected match characteristics of female tennis player. Kinesiol Slov. 2011; 17(2): 14-24.

6. ITF. Rules of Tennis. London; 2012.

7. Sanz D. Wheelchair Tennis. Barcelona: Paidotribo; 2003.

8. Goosey-Tolfrey VL, Moss AD. Wheelchair velocity of tennis players during propulsion with and without the use of racquets. Adapt Phys Act Q. 2005; 22: 291-301.

9. Sánchez-Pay A, Torres-Luque G, Fernandez-García ÁI, SanzRivas D. Análisis de la influencia de la superficie de juego en individual masculino en el tenis en silla de ruedas. CCD. 2013; 8(9): 217-222.

10. Katić R, Milat S, Zagorac N, Durović N. Impact of game elements on tennis match outcome in Wimbledon and Roland Garros 2009. Coll Antropol. 2011; 35(2): 341-346. http://www.ncbi.nlm.nih. gov/pubmed/21755700.

11. Ntoumanis N. A Step-by-Step Guide to SPSS for Sport and Exercise Studies. London: Routledge; 2001.

12. Tabachnick BG, Fidell LS. Using Multivariate Statistics (3rd Edition). New York: Harper Collins; 2001.

13. Brown E, O'Donoghue P. Gender and Surface Effect on Elite Tennis Strategy. Coach Sport Sci Rev. 2008; 46(15): 9-11.

14. Gillet E, Leroy D, Thouvarecq R, Stein J-F. A notational analysis of elite tennis serve and serve-return strategies on slow surface. J Strength Cond Res. 2009; 23(2): 532-539. doi:10.1519/ JSC.0b013e31818efe29.

15. Cross R, Pollard G. Grand Slam men's singles tennis 1991-2009. Serve speeds and other related data. Coach Sport Sci Rev. 2009; 16(49): 8-10.

16. Filipčič T, Filipčič A, Berendijas T. Comparison of game characteristics of male and female tennis players at Roland Garros 2005. Acta Univ Palacki Olomuc Gymnica. 2008; 38(3): 21-28. 


\section{Corresponding author}

Alejandro Sánchez-Pay

Universidad de Murcia, Murcia, Spain

Email: aspay@um.es

Manuscript received on April 28, 2017

Manuscript accepted on May 27, 2017

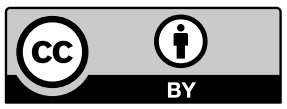

Motriz. The Journal of Physical Education. UNESP. Rio Claro, SP, Brazil - eISSN: 1980-6574 - under a license Creative Commons - Version 3.0 